\title{
Long-Term Neurological and Psychological Distress Symptoms among Smallholder Farmers in Costa Rica with a History of Acute Pesticide Poisoning
}

\author{
Andrea Farnham 1,2,*®D, Samuel Fuhrimann ${ }^{1,2,3}$, Philipp Staudacher ${ }^{4,5} \mathbb{D}^{0}$, Marcela Quirós-Lépiz ${ }^{6}$, \\ Carly Hyland ${ }^{6,7}$, Mirko S. Winkler ${ }^{1,2}$ and Ana M. Mora ${ }^{6,7}$ (D) \\ 1 Swiss Tropical and Public Health Institute, Socinstrasse 57, 4051 Basel, Switzerland; \\ samuel.fuhrimann@swisstph.ch (S.F.); mirko.winkler@swisstph.ch (M.S.W.) \\ 2 Swiss TPH, University of Basel, Petersplatz 1, 4001 Basel, Switzerland \\ 3 Institute for Risk Assessment Sciences (IRAS), Utrecht University, P.O. Box 80177, \\ 3508 TD Utrecht, The Netherlands \\ 4 Swiss Federal Institute of Aquatic Science and Technology (Eawag), Ueberlandstrasse 133, \\ 8600 Dübendorf, Switzerland; Philipp.Staudacher@eawag.ch \\ 5 Institute of Biogeochemistry and Pollutant Dynamics, Department of Environmental Systems Science, \\ ETH Zürich, Universitätstrasse 16, 8092 Zürich, Switzerland \\ 6 Central American Institute for Studies on Toxic Substances, Universidad Nacional, \\ Heredia 83-3000, Costa Rica; mquiroslepiz@gmail.com (M.Q.-L.); chyland@berkeley.edu (C.H.); \\ animora@berkeley.edu (A.M.M.) \\ 7 Center for Environmental Research and Children's Health (CERCH), School of Public Health, \\ check for \\ * Correspondence: andrea.farnham@swisstph.ch
}

Citation: Farnham, A.; Fuhrimann, S.; Staudacher, P.; Quirós-Lépiz, M.;

Hyland, C.; Winkler, M.S.; Mora, A.M.

Long-Term Neurological and

Psychological Distress Symptoms

among Smallholder Farmers in Costa Rica with a History of Acute Pesticide Poisoning. Int. J. Environ. Res. Public Health 2021, 18, 9021. https:// doi.org/10.3390/ijerph18179021

Academic Editor: Paul B. Tchounwou

Received: 14 July 2021

Accepted: 24 August 2021

Published: 26 August 2021

Publisher's Note: MDPI stays neutral with regard to jurisdictional claims in published maps and institutional affiliations.

\begin{abstract}
Studies suggest that acute pesticide poisonings (APP) may be linked with long-term neurological effects. To examine long-term neurological and psychological distress symptoms associated with having experienced an APP, we conducted a cross-sectional study of 300 conventional and organic smallholder farmers from Zarcero County, Costa Rica, May-August 2016. We collected self-reported data on sociodemographic characteristics, occupational history, pesticide exposure, APPs, neurological and psychological distress symptoms (using the Brief Symptom Inventory (BSI)). Adjusted logistic regression models were fit. A total of $14 \%$ of the farmers ( $98 \%$ male) reported experiencing at least one APP during their lifetime. Self-reported APP was associated with neurological symptoms during the 12 months prior to interview (e.g., fainting (Odds Ratio: 7.48, 95\% Confidence Interval: $1.83,30.74)$, shaking hands $(3.50 ; 1.60,7.60)$, numbness/tingling in hands or feet $(3.23 ; 1.66$, 6.32), insomnia $(2.53 ; 1.34,4.79)$, accelerated heartrate $(2.42 ; 1.03,5.47)$, dizziness $(2.38 ; 1.19,4.72)$, increased irritability/anger $(2.37 ; 1.23,4.55)$, low energy $(2.33 ; 1.23,4.46)$, and difficulty concentrating $(2.01 ; 1.05,3.85))$. Farmers who reported an APP in the ten years prior to interview experienced increased odds of abnormal BSI scores for hostility $(4.51 ; 1.16,17.70)$ and paranoid ideation $(3.76 ; 0.99$, 18.18). Having experienced an APP may be associated with long-term neurological and psychological distress symptoms.
\end{abstract}

Keywords: Costa Rica; pesticides; agriculture; farmers; pesticide poisoning; environmental health

\section{Introduction}

Occupational exposure to pesticides is ubiquitous among farmers worldwide [1] and its adverse effects on human health are a well-documented threat [2,3]. The burden of pesticides on health is particularly high in low- and middle-income countries (LMICs), due in part to pesticide applicators with less education, limited access to personal protective equipment $[4,5]$, larger agricultural populations, and fewer or less enforced regulations around pesticide use $[2,6,7]$. It is estimated that $99 \%$ of deaths from acute pesticide poisonings (APPs) occur in LMICs, despite the fact that these countries only use $20 \%$ of the 
pesticides produced internationally [8]. The true burden of APPs in LMICs is unknown, but previous studies have indicated that as few as $5 \%$ of cases are recorded by the official national registries $[7,9]$. While European countries have developed legislation to restrict the use of hazardous pesticides such as glyphosate, the use of pesticides in developing countries has grown rapidly without similar regulation [1].

Quantification of the burden of APPs in LMICs is made more challenging by the fact that their clinical presentation varies by pesticide class and sometimes by active ingredient [2,7]. Poisoning by organophosphate pesticides and carbamates (acetylcholinesterase inhibiting insecticides) is associated with multiple symptoms, including headache, dizziness, bradycardia, vomiting, and paralysis, among others [2]. Poisoning by herbicides such as paraquat, on the other hand, is associated with mucous membrane and airway irritation, abdominal pain, diarrhea, and vomiting, among others [2]. The non-specificity of these symptoms means that it is difficult to conclusively diagnose an APP without immediate confirmation via a doctor visit, which is often not available in LMICs; however, previous studies have suggested that recall accuracy of exposures to pesticide classes or groups is good (range $=0.6-0.9$ ) and that self-report of previous APPs is better than using medical records due to under-reporting [10-14].

Studies in both LMIC and high-income countries have suggested that there may be long-term health effects of APPs [15-25]. Two studies in Ethiopia and South Africa have reported associations of APPs with adverse long-term neurobehavioral outcomes, such as dizziness, sleepiness, headache, and overall neurological symptom scores $[15,16]$. Several studies in the United States and LMICs have also linked APPs with short and long-term psychological distress symptoms, including suicide, aggression, and depression [18-23,26]. However, disentangling chronic effects of past APPs from the ongoing effects of low-level pesticide exposure remains challenging, especially in LMICs where the burden of APPs is the highest $[8,27,28]$. By comparing farmers who switched from conventional farming practices (i.e., intensive use of synthetic pesticides) to organic farming practices (i.e., no use of synthetic pesticides), it is possible to assess whether lingering symptoms of past APPs remain even in those who no longer use synthetic pesticides. In our study of smallholder farmers from Costa Rica, we aimed to assess the associations of past self-reported APPs with (i) sociodemographic characteristics of farmers, (ii) frequency of neurological symptoms during the 12 months prior to the interview, and (iii) psychological distress symptoms during the month prior to interview. To our knowledge, we present the first study to look at a wide range of neurological and psychological distress symptoms associated with having experienced an APP in both conventional and organic farmers.

\section{Materials and Methods}

\subsection{Study Design and Participants}

We conducted a cross-sectional study of 300 smallholder farmers (273 men, 27 women aged 18-75) in Zarcero County, Costa Rica, between May and August 2016 [29]. This study is part of the larger Pesticide Use in Tropical Settings (PESTROP) project, which aims to assess the interactions between pesticide use-related environmental exposure, human health effects, and institutional determinants in two tropical agricultural settings (i.e., Zarcero Country in Costa Rica and Wakiso District in Uganda) [30]. The PESTROP project's subject recruitment and procedures have been described in detail elsewhere $[5,29,30]$. Briefly, conventional farms in the study area were selected using a random spatial sampling methodology and smallholder land-use data. Organic farms were chosen based on a list of farms from the local organic farmers' association or from in-person identification. Farmers were eligible to participate if they were farm owners, permanent workers, or temporary pesticide applicators aged $\geq 18$ years who owned or worked in farms located in the study area. They were ineligible if they had a diagnosis of psychiatric disease or used psychopharmacological medications. The active ingredients most commonly applied by the farmers in the 12 months before the study visit were the fungicide chlorothalonil, the herbicides paraquat and glyphosate, and the pyrethroid insecticide cypermethrin [5]. There 
was high variability in weekly pesticide exposure scores both within and between workers at the time of the interview, with limited protection of hands (gloves), eyes (glasses) and airways (masks or respirators) [4].

The present study was approved by the human subjects committee of the Universidad Nacional in Costa Rica (UNA-CECUNA-ACUE-04-2016) and Ethical Board of the Ethikkommission Nordwest- und Zentralschweiz in Switzerland (EKNZ-UBE 2016-00771). Written informed consent was obtained from all study participants. The study was carried out in accordance with The Code of Ethics of the World Medical Association (Declaration of Helsinki) for experiments involving humans and the Uniform Requirements for manuscripts submitted to Biomedical journals.

\subsection{Occupational Pesticide Exposure and Sociodemographic Characteristics}

We administered a structured questionnaire to farmers to collect data on sociodemographic characteristics and occupational history. To assess previous occupational pesticide exposure, we asked farmers the age at which they started working in agriculture and using pesticides, their work history in organic or conventional farms, and if they handled/ sprayed pesticides (specifically the 15 pesticide active ingredients most commonly used in the study area in 2014-2015) [4] during the 12 months prior to interview. To assess recent pesticide exposure, we asked if they had handled or applied pesticides during the week prior to interview and the specific pesticide active ingredients. The details can be found in Table 1 .

Table 1. Socio-demographic and occupational characteristics of the study population ( $n$ (\%) or median (P25-P75)), Zarcero County, Costa Rica, 2016, disaggregated by those who had experienced at least one acute pesticide poisoning (APP) and those who had not. World Health Organization (WHO) pesticide toxicity classifications were used.

\begin{tabular}{|c|c|c|}
\hline Characteristics & $\begin{array}{l}\text { Farmers Who Never Experienced APP } \\
\qquad(n=257)\end{array}$ & $\begin{array}{c}\text { Farmers Who Experienced at Least } \\
\text { One APP }(n=43)\end{array}$ \\
\hline Age (years) & $31.0(24.0-46.0)$ & $50.0(38.5-53.5)$ \\
\hline \multicolumn{3}{|l|}{ Sex } \\
\hline Male & $231(89.9)$ & $42(97.7)$ \\
\hline Female & $26(10.1)$ & $1(2.3)$ \\
\hline \multicolumn{3}{|l|}{ Marital status } \\
\hline Married or living as married & $150(58.4)$ & $33(76.7)$ \\
\hline Single & $99(38.5)$ & $7(16.3)$ \\
\hline Separated/divorced/widowed & $8(3.1)$ & $3(7.0)$ \\
\hline \multicolumn{3}{|l|}{ Job position } \\
\hline Farm owner & $86(33.5)$ & $27(62.8)$ \\
\hline Farmworker & $171(66.5)$ & $16(37.2)$ \\
\hline \multicolumn{3}{|l|}{ Country of birth } \\
\hline Costa Rica & $145(56.4)$ & $32(74.4)$ \\
\hline Nicaragua & $112(43.6)$ & $11(25.6)$ \\
\hline Education (years) & $6.0(5.0-8.0)$ & $6.0(6.0-6.0)$ \\
\hline \multicolumn{3}{|l|}{ Smoking habits } \\
\hline Never & $129(50.2)$ & $21(48.8)$ \\
\hline Former & $70(27.3)$ & $17(39.5)$ \\
\hline Current & $58(22.6)$ & $5(11.6)$ \\
\hline Number of drinks per week & $0.0(0.0-4.0)$ & $0(0.0-0.0)$ \\
\hline Time applying pesticides (years) & $14.0(7.0-28.0)$ & $34.0(23.5-38.5)$ \\
\hline \multicolumn{3}{|c|}{ Applicator of synthetic pesticides at time of interview } \\
\hline No & $68(26.5)$ & $12(27.9)$ \\
\hline Yes & $189(73.5)$ & $31(72.1)$ \\
\hline Household income (colones) & $320,000(260,000-500,000)$ & $320,000(228,000-600,000)$ \\
\hline Household size & $4.0(3.0-5.0)$ & $4.0(2.5-5.0)$ \\
\hline
\end{tabular}


Table 1. Cont.

\begin{tabular}{lcc}
\hline \multicolumn{1}{c}{ Characteristics } & $\begin{array}{c}\text { Farmers Who Never Experienced APP } \\
(\boldsymbol{n}=\mathbf{2 5 7 )}\end{array}$ & $\begin{array}{c}\text { Farmers Who Experienced at Least } \\
\text { One APP }(\boldsymbol{n}=\mathbf{4 3})\end{array}$ \\
\hline Training in safe practices for pesticide use & $98(45.4)$ & $25(65.8)$ \\
No & $118(45.9)$ & $13(30.2)$ \\
Yes & $98(45.4)$ & $25(65.8)$ \\
\hline Pesticide use at time of interview & & $8.0(4.0-21.0)$ \\
$\quad$ Time spent using pesticides & $8.0(4.0-13.0)$ & $37(86.0)$ \\
(hours/week) & $4(9.8)$ \\
\hline Used extremely or highly toxic pesticides in the last week (WHO classification Ia or Ib) & $200(77.8)$ \\
$\quad$ No & $34(14.5)$ & \\
Yes &
\end{tabular}

\subsection{APPs and Associated Neurological and Psychological Distress Symptoms}

We asked farmers if they had ever had an APP ("In your entire life, have you ever suffered a pesticide poisoning?") and if they had, how many times. For each APP, we also asked when it occurred and if it was confirmed by a doctor.

All farmers (regardless of previous APP) were asked if they had experienced any symptoms of APP (e.g., excessive salivation, lacrimation, vomiting, diarrhea) during the 12 months prior to interview (see Figure 1 for complete list of symptoms). The list of 31 symptoms was based on previous studies of Latin American farmworkers [22,31,32]. The farmers were asked to report the frequency of the symptom in the last 12 months on a scale from 0 to 4 (never, once in the last 12 months, once a month, once a week, more than once a week). Mean frequency of symptoms among different subgroups (e.g., those who had experienced an APP vs. those who had not) was then calculated by summing the total frequencies for each symptom divided by the total number of non-missing responses in that subgroup. Symptom occurrence was not used to define whether they had an APP, as clinical presentation can vary widely based on the poisoning agent and the non-specificity of symptoms makes it difficult to definitively diagnose all cases of APP [2].

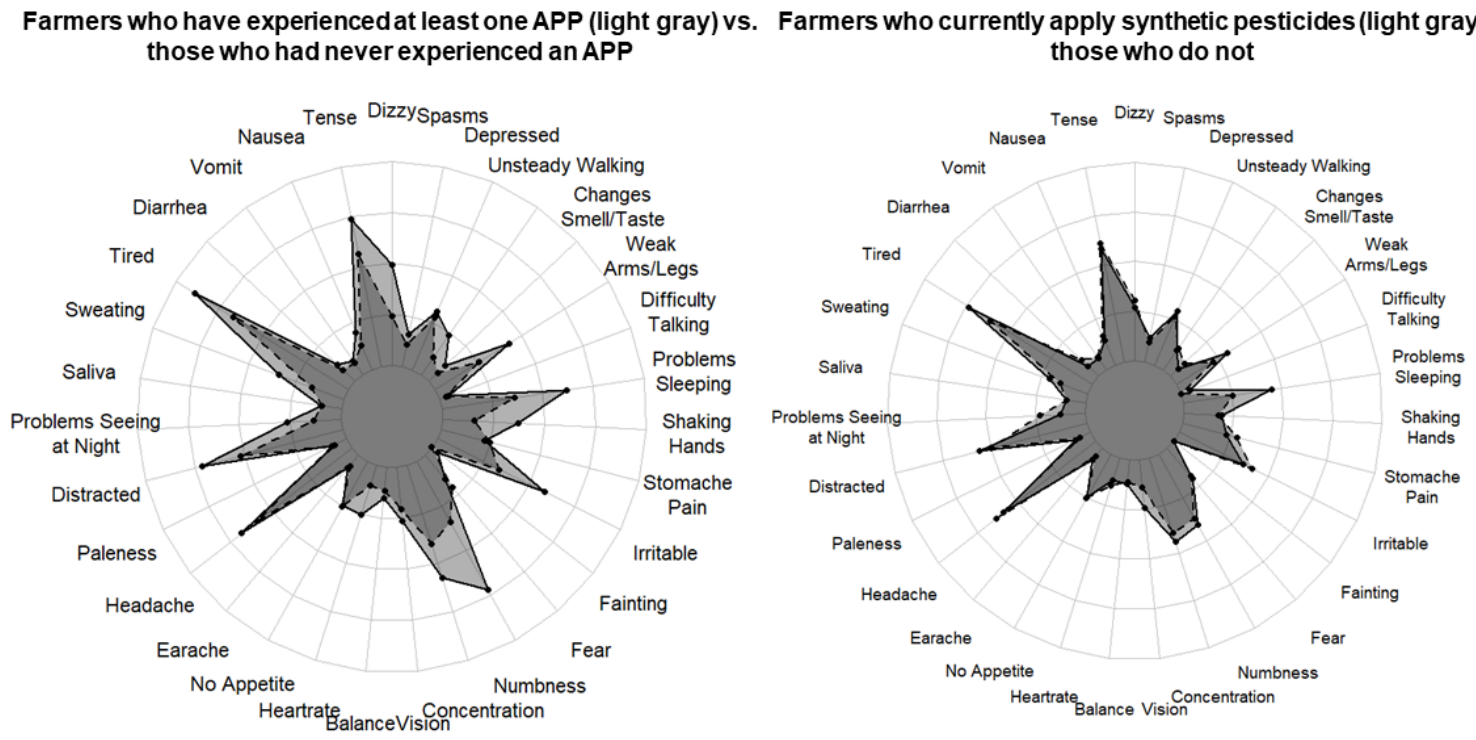

Figure 1. A comparison of the mean frequency of symptoms reported during the 12 months prior to interview by farmers who had experienced at least one APP ( $n=43$, in light gray) vs. those who had never suffered from an APP $(n=257$, in dark gray) is on the left. As a sensitivity analysis, a comparison of the mean frequency of symptoms reported during the 12 months prior to interview by farmers currently applying synthetic pesticides (e.g., conventional farmers, $n=220$, in light gray) vs. those who do not currently apply synthetic pesticides (e.g., organic farmers, $n=80$, in dark gray) is on the right. Symptom frequency was rated on a scale from 1 (one time in the year) to 4 (more than once a week). 
We administered the Spanish version of Brief Symptom Inventory (BSI) [33] to all farmers to assess the prevalence of psychological distress symptoms in the month prior to interview. The BSI is a standardized questionnaire of 53 items that has been successfully used in Latin American populations [22,34,35]. This instrument was originally designed to be self-administered, but because many farmers had low literacy, two psychometricians administered it verbally to all study participants using a visual scoring scale of 0 to 4 (never, rarely, sometimes, often, almost all the time). The BSI measures nine dimensions of psychological distress: somatization, obsession-compulsion, interpersonal sensitivity, depression, anxiety, hostility, phobic anxiety, paranoid ideation, and psychoticism. We calculated symptom dimension-specific scores dividing the subscores by the number of questions within the dimension. We also calculated the Global Severity Index (GSI), a measure of general psychological distress, by dividing the sum of scores of all BSI questions by the number of questions. We then normalized domain-specific and GSI scores to Tscores $($ mean $=50$, standard deviation $(\mathrm{SD})=10)$, using gender-specific data from the BSI manual [33]. Lastly, we dichotomized all scores using a cut-off T-score of $\geq 63$, which is considered a clinically relevant level of distress [33]. Psychometricians were blinded to the exposure status of the participants.

\subsection{Statistical Analyses}

We calculated descriptive statistics for all variables to describe the characteristics of the study population disaggregated by whether they had experienced an APP (Table 1).

To determine whether having experienced an APP was associated with key sociodemographic and occupational characteristics selected a priori using a causal diagram (age, sex, nationality, marital status, years of education, being a farm owner vs. a farm worker, type of farm at time of interview, having received training in safe practices for pesticide use, years of pesticide application), we first ran unadjusted logistic regression models. We then fitted a multivariate logistic regression model with explanatory variables whose $p$-value in the bivariate analyses was $<0.20$ (thus omitting type of farm at time of interview and years of education from the full model). Years of pesticide application was omitted from the model because it was highly correlated with age (Kendall's tau $=0.78, p<0.001$ ); age was chosen to remain because it was not subject to recall bias and there was virtually no missing data. Odds ratios (ORs) and associated $95 \%$ confidence intervals (CI) were reported.

To determine whether overall mean frequency of symptoms reported differed between those who had previously experienced an APP and those who had not, we conducted a two-way analysis of variance (ANOVA) analysis. If the ANOVA results were significant, we ran a Tukey's test to compare individual symptom frequencies while adjusting for multiple testing. We then fitted ordinal logistic regression models for the frequency of each health symptom during the 12 months prior to interview (outcome) regressed on ever having experienced an APP (yes/no, predictor) while adjusting for age, restricting to men (due to the low number of women having experienced an APP $(n=1)$ ), and using the polr command from the MASS package in R Statistical Software. We adjusted for age and sex as they were likely confounders (associated with experiencing an APP and the frequency of symptoms). As a sensitivity analysis, the same two-way ANOVA analysis was conducted on those who applied synthetic pesticides at the time of the interview and non-applicators, to see whether the overall mean frequency of symptoms reported reflected "current" exposure to synthetic pesticides.

To model whether having experienced an APP predicted clinically significant psychological distress based on BSI scores, we fitted logistic regression models for each symptom dimension and the GSI using dichotomized T-scores representing clinically relevant distress ( 1 : T-score $\geq 63 ; 0$ : T-score $<63$ ). We adjusted all models for age, education, and synthetic pesticide use at the time of the interview, as these are previously reported confounders in the literature [22]. All analyses were conducted using R Statistical Software version 3.6.1 [36]. 


\section{Results}

\subsection{Descriptive Statistics of the Study Population}

About $14 \%(n=43)$ of farmers reported at least one APP during their lifetime, with $3 \%(n=8)$ reporting more than one (maximum $=10$ APPs). Of the 72 APPs reported, $36 \%(n=26)$ were confirmed by a doctor, $76 \%(n=55)$ occurred to farmers working in conventional farms at the time of interview, and $82 \%(n=59)$ were able to be approximated by the farmer to a year (time range $=1972-2015$ ). Of the 59 APPs reported by farmers who remembered the date the event occurred, only $11(19 \%)$ took place in the 10 years prior to the interview. All farmers working in organic farms at the time of the interview who had experienced an APP $(n=7 / 43)$ were working in conventional farms at the time of their poisoning.

Farmers who had experienced at least one APP were mostly male (98\%), older (median age 50.0 vs. 31.0 years), had less education (completed a high school education $7 \%$ vs. $15 \%$ ), had spent more years applying pesticides (median years 34.0 vs. 14.0), and were more likely to report receiving training on safe practices for pesticide use (66\% vs. $45 \%$ ) compared to those who had never experienced an event (Table 1). More Costa Rican born farmers reported having experienced at least one APP $(18 \%, n=32 / 177)$ than those Nicaraguan born $(9 \%, n=11 / 123)$.

Pesticide use patterns at the time of the interview were similar between those who had experienced an APP and those who had not. Both groups reported using pesticides for a median of $8 \mathrm{~h}$ per week and using pesticides classified by the World Health Organization (WHO) as extremely or highly toxic [37] during the week (10\% vs. 15\%) and the 12 months ( $58 \%$ vs. $65 \%$ ) prior to interview.

\subsection{Sociodemographic Predictors of Having Experienced an APP}

In unadjusted models, each increasing year of age (OR: 1.05, 95\% CI: 1.03, 1.08), male sex (OR: $4.73,95 \%$ CI: $0.96,85.51$ ), being married or living in a partnership (OR: 2.35, $95 \%$ CI: 1.15, 5.23), having received training in pesticide use (OR: 2.62, 95\% CI: 1.32, 5.21), being of Costa Rican nationality (OR: 2.25, 95\% CI: 1.12, 4.85), and being a farm owner (OR: $3.36,95 \%$ CI: 1.73, 6.68) were associated with increased odds of having experienced an APP. However, in the full model, only age remained associated with increased odds of experiencing an APP (OR: 1.04, 95\% CI: 1.01, 1.08).

\subsection{Self-Reported Neurological Symptoms During the 12 Months Prior to Interview}

The most common symptoms reported were feeling tired (69\%), having a headache $(65 \%)$, and feeling tense (64\%). Most neurological symptoms-except for loss of appetite, paleness, stomach pain, feeling fearful, and nausea-were more frequent in farmers those who had previously experienced an APP than in those who had not (Figure 1).

The frequency of symptoms was higher among farmers who had experienced an APP vs. those who had not (Figure 1, two-way ANOVA results $F=2.04, p<0.001$ ). The greatest absolute differences in symptom frequency between those who had experienced an APP and those who had not were observed for numbness or tingling in hands and feet (mean difference (MD): 0.93, 95\% CI: 0.19, 1.66), insomnia (MD: 0.63, 95\% CI: $-0.10,1.37$ ), dizziness (MD: $0.61,95 \% \mathrm{CI}:-0.12,1.35)$, more irritable or angry than normal (MD: 0.61 , $95 \%$ CI: $-0.12,1.35$ ), tired or low energy (MD: $0.54,95 \%$ CI: $-0.19,1.28$ ), shaking hands (MD: $0.52,95 \%$ CI: $-0.21,1.25)$, Table 1 ). The only symptom that remained significant after adjustment for multiple testing was numbness or tingling in hands and feet.

After adjusting for age, having experienced at least one APP was associated with increased odds of fainting (OR: 7.48, 95\% CI: 1.83, 30.74), shaking hands (OR: 3.50, 95\% CI: $1.60,7.60)$, numbness or tingling in hands or feet (OR: 3.23, 95\% CI: 1.66, 6.32), insomnia (OR: 2.53, 95\% CI: 1.34, 4.79), accelerated heart rate (OR: 2.42, 95\% CI: 1.03, 5.47), dizziness (OR: $2.38,95 \%$ CI: 1.19, 4.72), being more irritable or angry than normal (OR: 2.37, 95\% CI: $1.23,4.55)$, tired or low energy (OR: $2.33,95 \%$ CI: $1.23,4.46)$, and difficulty concentrating (OR: 2.01, 95\% CI: 1.05, 3.85; Table 2). 
Table 2. Frequency of neurological symptoms in the last 12 months associated with having experienced at least one APP (predictor) in male farmers $(n=273)$ in an ordinal logistic regression model. Symptom frequency was rated on a scale from 0 (never) to 4 (more than once a week). Odds ratios (OR) and their associated 95\% confidence intervals (CI) are reported.

\begin{tabular}{|c|c|c|}
\hline Symptom (Outcome) & Unadjusted OR (95\% CI) & Adjusted OR (95\% CI) \\
\hline Fainting & $4.99(1.38,17.40)$ & $7.48(1.83,30.74)$ \\
\hline Shaking hands & $2.39(1.17,4.75)$ & $3.50(1.60,7.60)$ \\
\hline Numbness or tingling in hands or feet & $3.30(1.73,6.27)$ & $3.23(1.66,6.32)$ \\
\hline Insomnia & $2.44(1.32,4.47)$ & $2.53(1.34,4.79)$ \\
\hline Accelerated heart rate & $2.38(1.06,5.09)$ & $2.42(1.03,5.47)$ \\
\hline Dizziness & $2.59(1.33,5.01)$ & $2.38(1.19,4.72)$ \\
\hline More irritable or angry than normal & $2.22(1.19,4.14)$ & $2.37(1.23,4.55)$ \\
\hline Tired or low energy & $2.10(1.14,3.91)$ & $2.33(1.23,4.46)$ \\
\hline Excessive salivation & $1.21(0.39,3.14)$ & $2.27(0.67,6.79)$ \\
\hline Changes in ability to smell and taste & $1.86(0.64,4.71)$ & $2.23(0.73,6.17)$ \\
\hline Difficulty concentrating & $1.91(1.02,3.53)$ & $2.01(1.05,3.85)$ \\
\hline Excessive sweating/perspiration & $1.90(0.85,3.99)$ & $1.89(0.82,4.11)$ \\
\hline Headache & $1.52(0.83,2.78)$ & $1.88(0.99,3.55)$ \\
\hline Distracted, forgetful, or confused & $2.05(1.11,3.82)$ & $1.87(0.99,3.54)$ \\
\hline Vomiting & $1.18(0.42,2.88)$ & $1.74(0.58,4.61)$ \\
\hline Difficulty seeing at night & $1.97(0.85,4.26)$ & $1.67(0.70,3.75)$ \\
\hline Unsteady walking & $1.93(0.77,4.43)$ & $1.59(0.62,3.73)$ \\
\hline Tense, anxious or nervous & $1.90(1.04,3.48)$ & $1.57(0.84,2.94)$ \\
\hline Nausea & $1.74(0.81,3.56)$ & $1.55(0.70,3.28)$ \\
\hline Difficulty talking & $1.20(0.27,3.87)$ & $1.49(0.32,5.31)$ \\
\hline Paleness & $1.11(0.36,2.85)$ & $1.41(0.44,3.90)$ \\
\hline Loss of hunger/appetite & $1.10(0.50,2.25)$ & $1.40(0.62,3.00)$ \\
\hline Weakness in arms and legs & $1.68(0.84,3.25)$ & $1.38(0.68,2.74)$ \\
\hline Earache & $1.18(0.42,2.87)$ & $1.33(0.46,3.42)$ \\
\hline Diarrhea & $1.23(0.52,2.66)$ & $1.12(0.46,2.49)$ \\
\hline Abdominal or stomach pain & $0.97(0.46,1.94)$ & $1.11(0.51,2.32)$ \\
\hline Blurred or double vision & $1.46(0.70,2.90)$ & $1.02(0.47,2.09)$ \\
\hline Difficulty maintaining equilibrium & $1.22(0.43,2.97)$ & $0.99(0.34,2.47)$ \\
\hline Felt scared/fear & $0.85(0.38,1.76)$ & $0.88(0.38,1.87)$ \\
\hline Depressed, indifferent, or withdrawn & $0.99(0.49,1.93)$ & $0.87(0.42,1.72)$ \\
\hline
\end{tabular}

In our sensitivity analysis, we found that farmers who applied/handled synthetic pesticides (e.g., conventional farmers) at the time of the interview reported a similar frequency of symptoms compared to non-applicators (e.g., organic farmers) (Figure 1, two-way ANOVA results $F=1.74, p=0.19$ ), suggesting that acute exposure to pesticides is unlikely to account for the difference in symptoms between those who had experienced an APP and those who had not. Only $4 \%(n=12)$ of farmers had reported changing their pesticide use practices in the 12 months prior to interview.

\subsection{Psychological Distress Symptoms During the Month Prior to Interview}

Overall, BSI dimension-specific scores were similar in farmers who had experienced an APP compared to those who had not (Table 3). However, the farmers who reported experiencing an APP during the 10 years prior to interview $(n=10)$ had higher obsessioncompulsion, depression, anxiety, hostility, phobic anxiety, paranoid ideation, and psychoticism BSI scores compared to farmers who had never suffered an event (Table 3). The latter findings are similar to those of a previous Costa Rican study of farmers who had experienced an APP in the one to three years prior to the interview (Table 3) [22]. Notably, our study population showed elevated scores in every BSI dimension compared with the BSI normative sample of 600 healthy German adults [33] (Appendix A). 
Table 3. Median (interquartile range (IQR)) Brief Symptom Inventory (BSI) descriptive parameters in farmers who reported a pesticide poisoning vs. those who did not. A higher score corresponds to a higher frequency of symptoms in that dimension in the past month in the study population. The last column compares the data from this study with that of a different 2010 study in Costa Rican farmers that administered the BSI to farmers that had experienced an acute pesticide poisoning (APP) in the previous one to three years [22].

\begin{tabular}{|c|c|c|c|c|}
\hline BSI Dimensions & $\begin{array}{l}\text { Never Experienced APP } \\
(n=257)\end{array}$ & $\begin{array}{l}\text { Experienced at Least One } \\
\text { APP during Their Lifetime } \\
\qquad(n=43)\end{array}$ & $\begin{array}{l}\text { Experienced at Least One APP } \\
\text { during the Last } 10 \text { Years }(n=10)\end{array}$ & $\begin{array}{l}\text { Farmers from a } 2010 \text { Costa } \\
\text { Rican Study Who had } \\
\text { Experienced one APP 1-3 Years } \\
\text { Previously }(n=43)[22]\end{array}$ \\
\hline Somatization & $0.29(0.0,0.57)$ & $0.29(0.07,0.64)$ & $0.36(0.07,1.11)$ & $0.86(0.08,1.65)$ \\
\hline Obsession-compulsion & $0.50(0.0,1.0)$ & $0.50(0.17,1.0)$ & $0.75(0.17,1.46)$ & $0.83(0.17,1.50)$ \\
\hline Interpersonal sensitivity & $0.25(0.0,0.75)$ & $0.25(0.0,0.75)$ & $0.25(0.06,0.94)$ & $0.50(0.0,1.0)$ \\
\hline Depression & $0.17(0.0,0.67)$ & $0.17(0.0,0.5)$ & $0.50(0.50,0.67)$ & $0.33(0.0,1.0)$ \\
\hline Anxiety & $0.17(0.0,0.67)$ & $0.33(0.0,0.75)$ & $0.58(0.08,1.17)$ & $0.40(0.0,1.0)$ \\
\hline Hostility & $0.20(0.0,0.4)$ & $0.20(0.0,0.4)$ & $0.60(0.20,1.15)$ & $0.40(0.0,0.80)$ \\
\hline Phobic anxiety & $0.0(0.0,0.4)$ & $0.0(0.0,0.4)$ & $0.40(0.20,0.90)$ & $0.40(0.0,1.0)$ \\
\hline Paranoid ideation & $0.80(0.2,1.2)$ & $0.80(0.2,1.2)$ & $1.00(0.85,1.40)$ & $0.0(0.0,0.8)$ \\
\hline Psychoticism & $0.20(0.0,0.8)$ & $0.20(0.0,0.6)$ & $0.60(0.40,1.25)$ & $0.25(0.0,0.75)$ \\
\hline Global Severity Index (GSI) & $0.34(0.11,0.75)$ & $0.38(0.18,0.62)$ & $0.59(0.42,0.97)$ & $0.71(0.28,1.15)$ \\
\hline
\end{tabular}

No differences were observed in the odds of clinically relevant psychological distress in those who had previously experienced an APP after adjusting for age, education, and whether or not they applied/handled synthetic pesticides at the times of the interview (Table 4). However, farmers who reported having experienced an APP in the 10 years prior to interview experienced increased odds of abnormal BSI scores for hostility (OR: 4.51, 95\% CI: 1.16, 17.70) and paranoid ideation (OR: 3.76, 95\% CI: 0.99, 18.18).

Table 4. Prevalence and odds of cases of mental health according to normalized T-scores on the Brief Symptom Inventory (BSI) (cutoff T-score $\geq 63$ ) in the study population.

\begin{tabular}{|c|c|c|c|c|c|c|}
\hline \multirow{2}{*}{ BSI Dimensions } & \multicolumn{2}{|c|}{ Never Experienced APP $(n=257)$} & \multicolumn{2}{|c|}{$\begin{array}{l}\text { Experienced at least One APP } \\
\text { during Their Lifetime }(n=43)\end{array}$} & \multicolumn{2}{|c|}{$\begin{array}{l}\text { Experienced at least One APP } \\
\text { during the Last } 10 \text { Years }(n=10)\end{array}$} \\
\hline & $\begin{array}{l}\text { Prevalence } \\
\quad n(\%)\end{array}$ & OR $(95 \%$ CI $)$ & $\begin{array}{l}\text { Prevalence } \\
\quad n(\%)\end{array}$ & OR $(95 \%$ CI $)$ & $\begin{array}{c}\text { Prevalence } \\
n(\%)\end{array}$ & OR $(95 \% \mathrm{CI})$ \\
\hline Somatization & $78(30.4)$ & 1.0 & $12(27.9)$ & $1.08(0.49,2.26)$ & $4(40.0)$ & $1.57(0.38,5.88)$ \\
\hline Obsession-compulsion & $61(23.7)$ & 1.0 & $9(20.9)$ & $1.05(0.44,2.33)$ & $3(30.0)$ & $1.38(0.29,5.22)$ \\
\hline Interpersonal sensitivity & $53(20.6)$ & 1.0 & $10(23.3)$ & $1.57(0.67,3.53)$ & $3(30.0)$ & $1.80(0.37,7.03)$ \\
\hline Depression & $57(22.2)$ & 1.0 & $7(16.3)$ & $0.82(0.31,1.92)$ & $2(20.0)$ & $0.91(0.13,3.94)$ \\
\hline Anxiety & $50(19.5)$ & 1.0 & $11(25.6)$ & $1.47(0.65,3.17)$ & $3(30.0)$ & $2.0(0.41,7.65)$ \\
\hline Hostility & $50(19.5)$ & 1.0 & $7(16.3)$ & $1.25(0.46,3.06)$ & $5(50.0)$ & $4.51(1.16,17.70)$ \\
\hline Phobic anxiety & $55(21.4)$ & 1.0 & 8 (18.6) & $1.10(0.44,2.53)$ & $4(40.0)$ & $2.55(0.62,9.52)$ \\
\hline Paranoid ideation & $101(39.3)$ & 1.0 & $19(44.2)$ & $1.55(0.77,3.11)$ & $7(70.0)$ & $3.76(0.99,18.18)$ * \\
\hline Psychoticism & $77(30.0)$ & 1.0 & $9(20.9)$ & $0.87(0.36,1.92)$ & $5(50.0)$ & $2.48(0.65,9.45)$ \\
\hline Global Severity Index (GSI) & $81(31.5)$ & 1.0 & $11(25.6)$ & $0.91(0.41,1.92)$ & $5(50.0)$ & $2.16(0.57,8.24)$ \\
\hline
\end{tabular}

* Borderline statistically significant.

\section{Discussion}

Our findings indicate that the prevalence of APP among farmers in Costa Rica is substantial (14\%) and having experienced an APP may be associated with long-term neurological effects, particularly dizziness, feeling tired or low energy, experiencing an accelerated heart rate, difficulty concentrating, numbness or tingling in hands or feet, fainting, being more irritable or angry than normal, shaking hands, and insomnia. These results were similar to those of previous studies investigating associations between APPs and neurological symptoms $[15,16,26,27]$. These neurological symptoms are unlikely to be related to pesticide exposure at the time of the interview, as the sensitivity analysis showed that farmers who apply/handled pesticides at the time of the interview reported a similar frequency of symptoms to those who did not. The fact that only age remained predictive for having had an APP in the past, after adjustment for all other demographic and occupational factors, suggests that the dominant factor driving APPs in this population may be the total amount of time exposed to pesticides (age was highly correlated with years 
of pesticide use). Psychological distress symptoms in the month prior to the interview were not associated with ever having experienced an APP, but the odds of abnormal BSI scores for those who had experienced an APP in the 10 years prior to interview were elevated.

Consistent persistent symptom patterns among farmers who experienced at least one APP suggest that there are lasting health consequences of experiencing an event. The fact that this pattern occurs even among current non-applicators further implies that the symptoms are not related to recent pesticide application, but instead lasting consequences of APPs that may have occurred years before.

While having experienced an APP overall did not appear to be associated with psychological distress symptoms in the last month, that those who had experienced a pesticide poisoning in the past 10 years had elevated BSI scores in eight dimensions compared to the rest of the study population is suggestive that more recent APPs may be associated with psychological distress. However, this number of recent APPs $(n=10)$ is small, which prevents us from making strong conclusions about psychological distress in those with a recent APP. More research is warranted, but these results suggest that more recent pesticide poisonings may indeed affect mental functioning, and that this effect diminishes over time. This link between a recent APP and psychological distress as measured by the BSI was also shown in a cross-sectional 2010 study of banana workers in Costa Rica [22] and depressive symptoms were associated with a recent APP in farmers in other studies [20,21,38], providing further evidence for this hypothesis. It may also be that the association depends on the severity of the APP [38], which could not be measured by this study. Future studies should focus on psychological distress symptoms in those with recent APPs in LMICs, and especially addressing causality. In addition, our entire study population reported elevated psychological distress scores compared to the BSI normative population [33], suggesting that other factors may be impacting the neurological health of our study aside from pesticide use.

Another potential explanation for our findings may be that farmers that experienced an APP also experienced a higher rate of cumulative long-term exposure to pesticides over time, which may in turn lead to chronic health effects. Chronic long-term exposure to pesticides may be one explanation for the elevated reporting of psychological distress symptoms among the entire study population. Previous studies have reported that chronic high exposure to pesticides without an APP is also associated with depressive symptoms $[15,20,28]$, but these studies did not also investigate organic farmers that had stopped applying conventional pesticides as in this case. More focused studies (e.g., case-control, cohort) are needed to establish causality. In addition, a better measurement of long-term exposure to pesticides is needed to assess how long-term exposure to pesticides may interact with APPs to cause chronic health effects. Traditional urinary biomarkers of pesticide exposure are not useful in the context of measuring long-term effects of APPs, as they have a short half-life of only a few days [39]. To better assess chronic health effects, questionnaire-based algorithms could be used to estimate cumulative exposure to multiple pesticides over time [40].

Having experienced an APP did not appear to affect pesticide use practice: those who had experienced an APP continued to use highly and moderately toxic pesticides similarly to those who had not experienced a pesticide poisoning. The fact that those who had experienced an APP were more likely to have received training on pesticide application is counterintuitive; it may be that farmers were more likely to seek out training on pesticide application after they had experienced an APP, or that since they are older on average they had more opportunities to have received training in pesticide application, or that pesticide use practices have become safer over time, especially as there is still considerable exposure to pesticides in the study population [4]. Other studies in LMICs suggest that risk of APP is independent of previous knowledge about pesticide application [12]. It may also reflect the changing demographics of APPs over time, with more Nicaraguan migrants experiencing APPs in the last 10 years. 
Our study is limited by the self-reported nature of the APPs: only approximately a third were doctor-confirmed. However, previous studies have reported high reliability of self-reported APPs [16]. In addition, the proportion of farmers reporting an APP is very similar to other studies among agricultural workers in LMICs $[6,14,15]$. Further, previous research has found that minor cases of APP tend to be under-reported in self-reports [6]; this suggests that the true number of APP in this cohort is likely to be higher. This nondifferential exposure misclassification in our cohort would tend to under-estimate the true effect of an APP on health outcomes. In addition, it is difficult to completely adjust our analyses for the effects of current and chronic exposure to pesticides and isolate the effect of APPs retrospectively given the cross-sectional nature of the data. While comparing the symptoms of current pesticide applicators with non-applicators helps to isolate the effects of APPs, residual confounding cannot be ruled out. The small numbers in many health outcome categories prevent us from drawing strong conclusions on the link between individual symptoms and APPs. Nevertheless, our results suggest a link between APP and chronic health effects. Future research should involve a prospective design that measures continued pesticide exposure, establishing a concrete timeline. Finally, tools such as the BSI should be normed for populations in low- and middle-income countries, as differences in clinical relevance with populations in Western Europe are likely.

\section{Conclusions}

Our study suggests that the burden of persistent adverse health effects related to APPs is substantial in a population of smallholder farmers in Costa Rica. Having experienced an acute pesticide poisoning may be associated with long-term health symptoms such as dizziness, feeling tired or low energy, experiencing an accelerated heart rate, difficulty concentrating, numbness or tingling in hands or feet, fainting, being more irritable or angry than normal, shaking hands, and insomnia. Additionally, more recent APPs may be linked to psychological distress symptoms. Research and interventions to prevent and treat APPs are needed, such as reducing use of pesticides by changing laws around pesticide use and distribution, increasing the use of protective equipment, following cohorts of APPaffected farmers over time, providing immediate medical assistance to affected farmers, and strengthening education programs.

Author Contributions: Conceptualization, A.F., M.S.W., A.M.M.; methodology, A.F., S.F., P.S., M.S.W., A.M.M.; formal analysis, A.F.; investigation, S.F., P.S., A.M.M.; data curation, A.F., S.F., P.S.; writingoriginal draft preparation, A.F., A.M.M.; writing—review and editing, A.F., S.F., P.S., M.Q.-L., C.H., M.S.W., A.M.M.; visualization, A.F.; supervision, M.S.W., A.M.M.; project administration, S.F., M.S.W., A.M.M.; funding acquisition, M.S.W., S.F. and A.M.M. All authors have read and agreed to the published version of the manuscript.

Funding: This research was funded by Swiss Network for International Studies (SNIS), Geneva, Switzerland, Universidad Nacional (UNA), Heredia, Costa Rica, Swiss Federal Institute of Aquatic Science and Technology (Eawag), Dübendorf, Switzerland and the Forschungsfonds of the University of Basel, Basel, Switzerland. The funding source had no role in the study design, collection, analysis, or interpretation of data, in the writing of the report, or the decision to submit the manuscript for publication.

Institutional Review Board Statement: The present study was approved by the human subjects committee of the Universidad Nacional in Costa Rica (UNA-CECUNA-ACUE-04-2016) and Ethical Board of the Ethikkommission Nordwest- und Zentralschweiz in Switzerland (EKNZ-UBE 201600771). Written informed consent was obtained from all study participants. The study was carried out in accordance with The Code of Ethics of the World Medical Association (Declaration of Helsinki) for experiments involving humans and the Uniform Requirements for manuscripts submitted to Biomedical journals.

Informed Consent Statement: Informed consent was obtained from all subjects involved in the study. 
Data Availability Statement: The data presented in this study are available on request from the corresponding author with permission from the participating institutions. The data are not publicly available due to data ownership and privacy issues.

Acknowledgments: A transdisciplinary team comprised of practitioners from the Ugandan NGO Uganda National Association of Community and Occupational Health (UNACOH) in collaboration with researchers from the Central American Institute for Studies on Toxic Substances (IRET), Universidad Nacional (UNA), Heredia, Costa Rica, Makerere University, Uganda, the Swiss Institute for Tropical and Public Health (Swiss TPH), the Swiss Federal Institute of Aquatic Science and Technology (Eawag) and the Institute of Political Science (IPW) at University of Bern, Switzerland conducted the research funded by the Swiss Network for International Studies (SNIS), UNA, and Eawag. We specifically thank the teams involved in the fieldwork organization and data collection in Costa Rica (A. Alfaro, A Campos, S Colombari, G Rodríguez, A Ulloa, H Wey) and Uganda.

Conflicts of Interest: The authors declare no conflict of interest. The funders had no role in the design of the study; in the collection, analyses, or interpretation of data; in the writing of the manuscript, or in the decision to publish the results.

\section{Appendix A}

Table 1. Mean frequency of symptoms during the 12 months prior to interview reported by Figure 1 , from 0 (never) to 4 (more than once a week).

\begin{tabular}{|c|c|c|c|}
\hline Symptom & $\begin{array}{c}\text { Farmers who Never Experienced } \\
\text { APP }(n=257)\end{array}$ & $\begin{array}{l}\text { Farmers who Experienced at } \\
\text { Least One APP }(n=43)\end{array}$ & Difference in Frequency \\
\hline Dizziness & 0.64 & 1.26 & 0.61 \\
\hline Tense, anxious or nervous & 1.43 & 1.86 & 0.43 \\
\hline Nausea & 0.75 & 0.53 & -0.22 \\
\hline Vomiting & 0.22 & 0.26 & 0.04 \\
\hline Diarrhea & 0.25 & 0.35 & 0.1 \\
\hline Tired or low energy & 1.69 & 2.23 & 0.54 \\
\hline More than normal sweating/perspiration & 0.84 & 0.88 & 0.04 \\
\hline More than normal salivation & 0.28 & 0.30 & 0.02 \\
\hline Difficulty seeing at night & 0.38 & 0.70 & 0.32 \\
\hline Distracted, forgetful, or confused & 1.31 & 1.79 & 0.48 \\
\hline Paleness & 0.24 & 0.21 & -0.03 \\
\hline Headache & 1.48 & 1.72 & 0.24 \\
\hline Earache & 0.21 & 0.26 & 0.05 \\
\hline Loss of appetite & 0.67 & 0.65 & -0.02 \\
\hline Accelerated heartrate & 0.30 & 0.67 & 0.37 \\
\hline Difficulty with balance & 0.33 & 0.42 & 0.09 \\
\hline Blurred or double vision & 0.55 & 0.70 & 0.15 \\
\hline Difficulty concentrating & 1.04 & 1.47 & 0.43 \\
\hline Numbness or tingling in hands or feet & 0.89 & 1.81 & $0.93 *$ \\
\hline Felt fearful & 0.55 & 0.42 & -0.13 \\
\hline Fainting & 0.04 & 0.14 & 0.1 \\
\hline More irritable or angry than normal & 0.88 & 1.49 & 0.61 \\
\hline Stomach pain & 0.65 & 0.58 & -0.07 \\
\hline Shaking hands & 0.43 & 0.95 & 0.52 \\
\hline Insomnia & 0.93 & 1.56 & 0.63 \\
\hline Difficulty talking & 0.13 & 0.16 & 0.03 \\
\hline Weakness in arms or legs & 0.67 & 1.09 & 0.42 \\
\hline Changes in ability to smell and taste & 0.19 & 0.33 & 0.14 \\
\hline Unsteady walking & 0.30 & 0.63 & 0.33 \\
\hline Depressed, indifferent, or withdrawn & 0.74 & 0.81 & 0.07 \\
\hline Spasms or involuntary movements & 0.33 & 0.44 & 0.11 \\
\hline
\end{tabular}

* indicates that there was a statistically significant difference in mean frequency. 


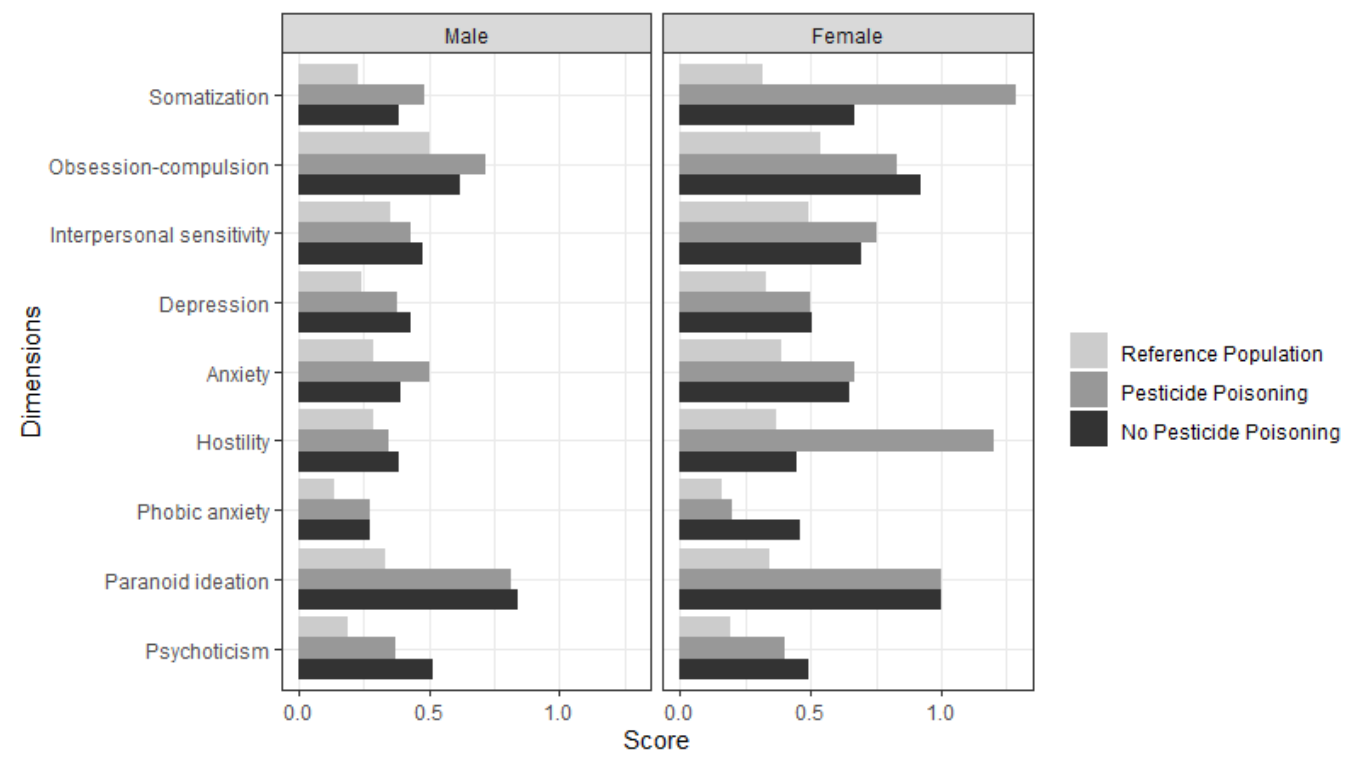

Figure A1. Mean scores on the Brief Symptom Inventory (BSI) dimensions of a normative reference population, farmers who had experienced at least one APP during their lifetime, and farmers who did not experience an APP, disaggregated by sex. The reference population comes from a normative sample of 600 healthy German adults, collected between 1995 and 1997 [33]. Note that only one woman reported an APP.

\section{References}

1. Sharma, A.; Kumar, V.; Shahzad, B.; Tanveer, M.; Sidhu, G.P.S.; Handa, N.; Kohli, S.K.; Yadav, P.; Bali, A.S.; Parihar, R.D.; et al. Worldwide pesticide usage and its impacts on ecosystem. SN Appl. Sci. 2019, 1, 1446. [CrossRef]

2. Thundiyil, J.G.; Stober, J.; Besbelli, N.; Pronczuk, J. Acute pesticide poisoning: A proposed classification tool. Bull. World Health Organ. 2008, 86, 205-209. [CrossRef]

3. Ohlander, J.; Fuhrimann, S.; Basinas, I.; Cherrie, J.W.; Galea, K.S.; Povey, A.C.; van Tongeren, M.; Harding, A.-H.; Jones, K.; Vermeulen, R.; et al. Systematic review of methods used to assess exposure to pesticides in occupational epidemiology studies, 1993-2017. Occup. Environ. Med. 2020. [CrossRef] [PubMed]

4. Fuhrimann, S.; Staudacher, P.; Lindh, C.; van Wendel de Joode, B.; Mora, A.M.; Winkler, M.S.; Kromhout, H. Variability and predictors of weekly pesticide exposure in applicators from organic, sustainable and conventional smallholder farms in Costa Rica. Occup. Environ. Med. 2020, 77, 40-47. [CrossRef] [PubMed]

5. Staudacher, P.; Fuhrimann, S.; Farnham, A.; Mora, A.M.; Atuhaire, A.; Niwagaba, C.; Stamm, C.; Eggen, R.I.L.; Winkler, M.S. Comparative Analysis of Pesticide Use Determinants Among Smallholder Farmers From Costa Rica and Uganda. Environ. Health Insights 2020, 14, 1178630220972417. [CrossRef] [PubMed]

6. Corriols, M.; Marin, J.; Berroteran, J.; Lozano, L.M.; Lundberg, I. Incidence of acute pesticide poisonings in Nicaragua: A public health concern. Occup. Environ. Med. 2009, 66, 205-210. [CrossRef] [PubMed]

7. Wesseling, C.; Corriols, M.; Bravo, V. Acute pesticide poisoning and pesticide registration in Central America. Toxicol. Appl. Pharmacol. 2005, 207, 697-705. [CrossRef] [PubMed]

8. Kesavachandran, C.N.; Fareed, M.; Pathak, M.K.; Bihari, V.; Mathur, N.; Srivastava, A.K. Adverse health effects of pesticides in agrarian populations of developing countries. Rev. Environ. Contam. Toxicol. 2009, 200, 33-52.

9. Corriols, M.; Marin, J.; Berroteran, J.; Lozano, L.M.; Lundberg, I.; Thorn, A. The Nicaraguan Pesticide Poisoning Register: Constant underreporting. Int. J. Health Serv. 2008, 38, 773-787. [CrossRef]

10. Engel, L.S.; Seixas, N.S.; Keifer, M.C.; Longstreth, W.T., Jr.; Checkoway, H. Validity study of self-reported pesticide exposure among orchardists. J. Expo. Anal. Environ. Epidemiol. 2001, 11, 359-368. [CrossRef] [PubMed]

11. Hoppin, J.A.; Yucel, F.; Dosemeci, M.; Sandler, D.P. Accuracy of self-reported pesticide use duration information from licensed pesticide applicators in the Agricultural Health Study. J. Expo. Sci. Environ. Epidemiol. 2002, 12, 313-318. [CrossRef]

12. Lekei, E.E.; Ngowi, A.V.; London, L. Farmers' knowledge, practices and injuries associated with pesticide exposure in rural farming villages in Tanzania. BMC Public Health 2014, 14, 389. [CrossRef] [PubMed]

13. Blair, A.; Tarone, R.; Sandler, D.; Lynch, C.F.; Rowland, A.; Wintersteen, W.; Steen, W.C.; Samanic, C.; Dosemeci, M.; Alavanja, M.C. Reliability of reporting on life-style and agricultural factors by a sample of participants in the Agricultural Health Study from Iowa. Epidemiology 2002, 13, 94-99. [CrossRef] [PubMed] 
14. Nigatu, A.W.; Bråtveit, M.; Moen, B.E. Self-reported acute pesticide intoxications in Ethiopia. BMC Public Health 2016, 16, 575. [CrossRef] [PubMed]

15. Negatu, B.; Vermeulen, R.; Mekonnen, Y.; Kromhout, H. Neurobehavioural symptoms and acute pesticide poisoning: A crosssectional study among male pesticide applicators selected from three commercial farming systems in Ethiopia. Occup. Environ. Med. 2018, 75, 283-289. [CrossRef] [PubMed]

16. London, L.; Nell, V.; Thompson, M.L.; Myers, J.E. Effects of long-term organophosphate exposures on neurological symptoms, vibration sense and tremor among South African farm workers. Scand. J. Work. Environ. Health 1998, 24, 18-29. [CrossRef]

17. Wesseling, C.; Keifer, M.; Ahlbom, A.; McConnell, R.; Moon, J.-D.; Rosenstock, L.; Hogstedt, C. Long-term Neurobehavioral Effects of Mild Poisonings with Organophosphate and n-Methyl Carbamate Pesticides among Banana Workers. Int. J. Occup. Environ. Health 2002, 8, 27-34. [CrossRef]

18. Kim, J.Y.; Park, S.J.; Kim, S.K.; Kim, C.S.; Kim, T.H.; Min, S.H.; Oh, S.S.; Koh, S.B. Pesticide exposure and cognitive decline in a rural South Korean population. PLoS ONE 2019, 14, e0213738.

19. Stallones, L.; Beseler, C.L. Assessing the connection between organophosphate pesticide poisoning and mental health: A comparison of neuropsychological symptoms from clinical observations, animal models and epidemiological studies. Cortex 2016, 74, 405-416. [CrossRef]

20. Beseler, C.L.; Stallones, L.; Hoppin, J.A.; Alavanja, M.C.; Blair, A.; Keefe, T.; Kamel, F. Depression and pesticide exposures among private pesticide applicators enrolled in the Agricultural Health Study. Environ. Health Perspect. 2008, 116, 1713-1719. [CrossRef]

21. Beseler, C.L.; Stallones, L. A cohort study of pesticide poisoning and depression in Colorado farm residents. Ann. Epidemiol. 2008, 18, 768-774. [CrossRef]

22. Wesseling, C.; van Wendel de Joode, B.; Keifer, M.; London, L.; Mergler, D.; Stallones, L. Symptoms of psychological distress and suicidal ideation among banana workers with a history of poisoning by organophosphate or n-methyl carbamate pesticides. Occup. Environ. Med. 2010, 67, 778-784. [CrossRef]

23. Beard, J.D.; Hoppin, J.A.; Richards, M.; Alavanja, M.C.; Blair, A.; Sandler, D.P.; Kamel, F. Pesticide exposure and self-reported incident depression among wives in the Agricultural Health Study. Environ. Res. 2013, 126, 31-42. [CrossRef] [PubMed]

24. Beard, J.D.; Umbach, D.M.; Hoppin, J.A.; Richards, M.; Alavanja, M.C.; Blair, A.; Sandler, D.P.; Kamel, F. Pesticide exposure and depression among male private pesticide applicators in the agricultural health study. Environ. Health Perspect. 2014, 122, 984-991. [CrossRef] [PubMed]

25. Curl, C.L.; Spivak, M.; Phinney, R.; Montrose, L. Synthetic Pesticides and Health in Vulnerable Populations: Agricultural Workers. Curr. Environ. Health Rep. 2020, 7, 13-29. [CrossRef] [PubMed]

26. Zhang, X.; Wu, M.; Yao, H.; Yang, Y.; Cui, M.; Tu, Z.; Stallones, L.; Xiang, H. Pesticide poisoning and neurobehavioral function among farm workers in Jiangsu, People's Republic of China. Cortex 2016, 74, 396-404. [CrossRef] [PubMed]

27. Ross, S.M.; Harrison, V. Organophosphates II. Neurobehavioural Problems Following Low-Level Exposure: Methodological Considerations for Future Research. In A Handbook of Environmental Toxicology: Human Disorders and Ecotoxicology; CAB International: Wallingford, UK, 2020.

28. Muñoz-Quezada, M.T.; Lucero, B.A.; Iglesias, V.P.; Muñoz, M.P.; Cornejo, C.A.; Achu, E.; Baumert, B.; Hanchey, A.; Concha, C.; Brito, A.; et al. Chronic exposure to organophosphate (OP) pesticides and neuropsychological functioning in farm workers: A review. Int. J. Occup. Environ. Health 2016, 22, 68-79. [CrossRef]

29. Fuhrimann, S.; Winkler, M.S.; Staudacher, P.; Weiss, F.T.; Stamm, C.; Eggen, R.I.; Lindh, C.H.; Menezes-Filho, J.A.; Baker, J.M.; Ramirez-Munoz, F.; et al. Exposure to Pesticides and Health Effects on Farm Owners and Workers From Conventional and Organic Agricultural Farms in Costa Rica: Protocol for a Cross-Sectional Study. JMIR Res. Protoc. 2019, 8, e10914. [CrossRef] [PubMed]

30. Winkler, M.S.; Atuhaire, A.; Fuhrimann, S.; Mora, A.M.; Niwagaba, C.; Oltramare, C.; Ramírez, F.; Ruepert, C.; Staudacher, P.; Weiss, F.; et al. Environmental Exposures, Health Effects and Institutional Determinants of Pesticide use in Two Tropical Settings. (working paper), Geneva. 31 March 2019. Available online: https://snis.ch/wp-content/uploads/2020/01/2014_Winkler_ Working-Paper.pdf (accessed on 24 August 2021).

31. Wesseling, C.; Aragon, A.; Rojas, M.; Blanco, L.; Lopez, L.; Soto, A.; Funez, A.; Ruepert, C.; Miranda, J.; Lopez, I. Efectos del Clorpirifos en la Salud de Trabajadores Bananeros de la Lima, Honduras; SALTRA, IRET-UNA, CISTA, UNAN-Leon: Heredia, Costa Rica, 2006.

32. Rodezno, R.A.; Lundberg, I.; Escalona, E. Development of a questionnaire in Spanish on neurotoxic symptoms. Am. J. Ind. Med. 1995, 28, 505-520. [CrossRef]

33. Derogatis, L.R. Brief Symptoms Inventory (BSI): Administration, Scoring and Procedures Manual 3rd edn. NCS Pearson, Inc.: Minneapolis, MN, USA, 1993. Available online: https://hazards.colorado.edu/nhcdata/chernobyl/ChData/ScalesInstruments/ Scales\%20and\%20Indices/Scale\%20Construction\%20Instructions / BSI.pdf (accessed on 24 August 2021).

34. Coelho, V.L.; Strauss, M.E.; Jenkins, J.H. Expression of symptomatic distress by Puerto Rican and Euro-American patients with depression and schizophrenia. J. Nerv. Ment. Dis. 1998, 186, 477-483. [CrossRef]

35. Hemmings, M.; Reimann, J.O.; Madrigal, D.; Velasquez, R.J. Predictors of scores on the Brief Symptom Inventory for ethnically diverse female clients. Psychol. Rep. 1998, 83, 800-802. [CrossRef] [PubMed]

36. R Core Team. R: A Language and Environment for Statistical Computing; R Foundation for Statistical Computing: Vienna, Austria, 2013; Available online: https:/ / www.r-project.org/index.html (accessed on 24 August 2021). 
37. WHO. The WHO Recommended Classification of Pesticides by Hazard and Guidelines to Classification 2009; World Health Organization: Geneva, Switzerland, 2010.

38. Kim, J.; Ko, Y.; Lee, W.J. Depressive symptoms and severity of acute occupational pesticide poisoning among male farmers. Occup. Environ. Med. 2013, 70, 303-309. [CrossRef] [PubMed]

39. Kim, J.H.; Stevens, R.C.; MacCoss, M.J.; Goodlett, D.R.; Scherl, A.; Richter, R.J.; Suzuki, S.M.; Furlong, C.E. Identification and characterization of biomarkers of organophosphorus exposures in humans. Adv. Exp. Med. Biol. 2010, 660, 61-71.

40. Fuhrimann, S.; Farnham, A.; Staudacher, P.; Atuhaire, A.; Manfioletti, T.; Niwagaba, C.B.; Namirembe, S.; Mugweri, J.; Winkler, M.S.; Portengen, L.; et al. Exposure to multiple pesticides and neurobehavioral outcomes among smallholder farmers in Uganda. Environ. Int. 2021, 152, 106477. 